ISSN 1981-416X

Licenciado sob uma Licença Creative Commons

(c) (1)

\title{
O paradoxo da educação brasileira: uma relação antagônica entre o princípio de realidade e o princípio de desempenho
}

The Brazilian education paradox: an antagonistic relation between the principle of reality and the principle of performance

La paradoja de la educación brasileña: una relación antagónica entre el principio de realidad y el principio de desempeño

\section{Adauto Lopes da Silva Filho, Fátima Maria Nobre Lopes*}

\section{Resumo}

O desenvolvimento da sociedade capitalista e tecnológica traz, em seu bojo, um paradoxo: ao mesmo tempo que desenvolve as potencialidades da razão humana, torna essa mesma razão um instrumento de manipulação e de poder. Tomando essas considerações, a partir do pensamento do filósofo Herbert Marcuse, o artigo objetiva demonstrar que esse paradoxo da sociedade, que determina o pensamento e as ações dos indivíduos, afirma-se também na educação brasileira e se expressa na relação antagônica entre o princípio de realidade e o princípio de desempenho amparado pela mais-repressão, pois, ao mesmo tempo que essa 
educação defende uma formação democrática, igualitária e cidadã, ela leva os indivíduos à alienação e ao sofrimento ao empreender tal formação com um caráter mercadológico. Apesar desse paradoxo que se instaura na sociedade e, em consequência, na educação, Marcuse defende a possibilidade de romper com a dominação que aí se estabelece, a fim de suprimir a mais-repressão, tendo em vista a aquisição de um princípio de realidade emancipatório.

Palavras-chave: Sociedade tecnológica. Paradoxo. Educação. Princípio de realidade. Princípio de desempenho.

\section{Abstract}

Development of capitalist and technological society brings a paradox: the potentialities of human reason are developed at the same time this reason becomes an instrument of power and manipulation. Taking this and the thoughts of Herbert Marcuse, this article aims to demonstrate that this very paradox of our society, which determines the individuals' actions and thinking, is also seen in Brazilian education, for it expresses itself in the antagonistic relationship between the principle of reality and the principle of performance supported by surplus-repression, since at the same time that this education defends a democratic and equality-based formation, it also leads subjects to alienation and suffering to perform its formation with a commodifying character. Despite this paradox which is established in society and education, Marcuse defends the possibility to break the domination that lies herein, in order to counteract surplus-repression, in sight for an emancipatory principle of reality.

Keywords: Technological society. Paradox. Education. Principle of reality. Principle of performance.

\section{Resumen}

El desarrollo de la sociedad capitalista y tecnológica trae en sí una paradoja. Simultáneamente, desarrolla las potencialidades de la razón humana y la convierte en un instrumento de manipulación y de poder. A partir del pensamiento del filósofo Herbert 
Marcuse, el artículo objetiva demostrar que esa paradoja de la sociedad, que determina el pensamiento y las acciones de los individuos, se afirma en la educación brasileña y se expresa en la relación antagónica entre el principio de realidad y el principio de desempeño amparado por la más represión, pues, al mismo tiempo que esa educación defiende una formación democrática, igualitaria y ciudadana, lleva a los individuos a la alienación y al sufrimiento cuando emprende tal formación por medio de un carácter mercadológico. A pesar de esta paradoja instaurada en la sociedad y, en consecuencia, en la educación, Marcuse defiende la posibilidad de romper la dominación que allí se establece, para suprimir la más represión, con miras a la adquisición de un principio de realidad emancipatorio.

Palabras clave: Sociedad tecnológica. Paradoja. Educación. Principio de realidad. Principio de desempeño.

\section{Introdução}

O paradoxo da educação brasileira não está fora do contexto social mais amplo; por conseguinte, ele segue os ditames do paradoxo que se instaurou na sociedade capitalista e/ou tecnológica.

Acompanhamos uma época em que a ciência e a tecnologia se desenvolveram a tal ponto que poderiam atender às necessidades humanas. No entanto, o mundo encantado da ciência e da tecnologia parece andar na contramão do processo de humanização. O que se percebe é que, quanto mais se desenvolve a ciência e a sociedade, mais aumenta a miséria, a opressão, a violência e a negação crescente dos valores humanos. Dessa situação resulta o principal paradoxo da sociedade tecnológica: ela proporcionou o desenvolvimento das potencialidades da razão humana, da razão iluminista, mas, ao mesmo tempo, a torna uma razão instrumental, quer dizer, a torna um instrumento de manipulação e de poder, inculcando nos indivíduos os ditames da sociedade padronizada pela exploração, competição e consumismo. 
Essa temática está bem delineada no pensamento do filósofo Herbert Marcuse, que denomina essa metamorfose de razão instrumental e/ou tecnológica. Segundo Marcuse, a transmutação da razão iluminista e filosófica em razão instrumental e tecnológica provocou a mais-repressão, que se expressa no princípio de desempenho como parâmetro do princípio de realidade. O paradoxo que aí se instaura invade toda a vida humana, e aqui podemos nos remeter à educação.

Partindo dessas considerações e tomando principalmente o pensamento de Marcuse, porém sem excluir outros autores, como Marx, Mészáros, Severino e Mesquida, o objetivo deste artigo volta-se para a tentativa de demonstrar que o paradoxo da sociedade capitalista e tecnológica incide também, no nosso caso, na educação brasileira, que se expressa na relação antagônica entre o princípio de realidade e o princípio de desempenho. O paradoxo central que se estabelece aqui, além de outros dele decorrentes, é o caráter da formação defendida na Lei de Diretrizes e Bases da Educação Brasileira, de 1996, como devendo ser democrática, igualitária e cidadã; no entanto, na sua prática, há uma tendência predominante de levar os indivíduos à alienação e ao sofrimento, ao empreender tal formação com um caráter mercadológico.

Todavia, na esteira do pensamento de Marcuse em relação à grande recusa, apontamos a necessidade e a possibilidade da supressão da mais-repressão, que se expressa no princípio de desempenho, a fim de se obter um novo princípio de realidade, princípio este que esteja voltado para os valores superiores do ser humano.

\section{O paradoxo da sociedade tecnológica sob a ótica de Marcuse}

Herbert Marcuse (1898-1979), filósofo alemão, foi um dos grandes teóricos da Teoria Crítica da Escola de Frankfurt. A sua contribuição destacou-se principalmente pela sua crítica ao paradoxo da Sociedade 
Tecnológica ${ }^{1}$, que promoveu o desenvolvimento da razão iluminista, mas, ao mesmo tempo, tornou essa razão, paradoxalmente, irracional, ao convertê-la em razão instrumental a favor do poder dominante. Desse modo, "a racionalidade do progresso agrava a irracionalidade de sua organização e direção" (MARCUSE, 1981, p. 100). Em consequência, emerge uma discrepância entre os ideais de liberdade, advogada pelo iluminismo, e o potencial autoritário e repressivo da sociedade tecnológica. Esse antagonismo "destaca-se como o arqui-inimigo, o próprio Anticristo: está sempre em toda parte; representa forças ocultas e sinistras, e a sua onipresença exige a mobilização total (MARCUSE, 1981, p. 100). Tomando as próprias palavras de Marcuse (1981, p. 100), podemos dizer que, "se as invenções técnicas que poderiam libertar o mundo da miséria e do sofrimento são usadas para a conquista ou para a criação de sofrimento", então podemos apontar aqui o grande paradoxo da sociedade tecnológica ou sociedade industrial avançada.

Portanto, o desenvolvimento e a alta capacidade da ciência e da tecnologia, que poderiam satisfazer as reais necessidades humanas, terminam por provocar carências e sofrimento ao envolver os indivíduos com a atração da produção de bens, sob a lógica do mercado e da dominação, de tal modo que faz submergir a bidimensionalidade da vida humana pela sua unidimensionalidade, pois os indivíduos introjetam os ditames da sociedade repressora e dominadora, tornando-se pseudamente felizes pelo consumo, competição, domínio de poder, etc. Essa sociedade, que gera um alto grau de satisfação pelo consumo e pela posse de bens, termina por encobrir a sua lógica de dominação. O preço dessa pseudossatisfação decorre da manipulação e do controle da sociedade desenvolvida sobre os seres humanos, como diz Marcuse (1999a, p. 148) abaixo:

1 Marcuse usa os termos "Sociedade Tecnológica", "Sociedade Científica", "Sociedade Industrial", "Sociedade Unidimensional" no mesmo sentido, ou seja, significando o caráter irracional e opressor da sociedade industrial desenvolvida, quer dizer, da sociedade capitalista. 
Sob as condições da sociedade industrial avançada, a satisfação está sempre ligada à destruição. A dominação da natureza está ligada à violação da natureza. A procura por novas fontes de energia está ligada ao envenenamento do meio ambiente. A segurança está ligada à servidão, o interesse nacional à expansão global. O progresso técnico está ligado ao controle e à manipulação progressivos dos seres humanos.

Pode parecer um tanto pessimista essa posição de Marcuse, principalmente em relação ao desenvolvimento da sociedade tecnológica. Não obstante, ele reconhece que esse desenvolvimento no início da modernidade definia o homem como um sujeito livre, ativo e autônomo, capaz de exteriorizar as suas capacidades e habilidades e "[...] o dever da sociedade era conceder ao indivíduo tal liberdade e eliminar todas as restrições à sua linha de ação racional" (MARCUSE, 1999b, p. 75). Portanto, o progresso tecnológico gerou as condições para libertar o homem do Antigo Regime, para possibilitar a sua emancipação e para atender às suas necessidades. Porém, no momento em que essa liberdade e necessidades são postas a serviço de uma sociedade que domina e determina as aspirações, os pensamentos e as ações dos indivíduos, paradoxalmente o progresso técnico gera uma nova forma de submissão e termina por padronizar a própria vida desses indivíduos, provocando uma nova submissão, embora diferente daquela do Antigo Regime. Nesse sentido, a razão iluminista, filosófica e crítica, própria da sociedade moderna na sua origem, transmutou-se em uma razão tecnológica, científica e instrumental.

A razão tecnológica ou instrumental torna-se totalitária na vida social dos homens, invadindo todas as esferas da sua existência e, assim, a dominação do capitalismo avançado se estende por toda parte. Isso é fruto da sociedade tecnológica, que, apesar de se afirmar como liberal e democrática, reduz essa democracia, como também o desenvolvimento do potencial humano, ao consumismo e ao mercado. É nesse sentido que a (ir)racionalidade da sociedade tecnológica impõe-se de forma abrangente em todas as dimensões da vida social: na família, nos meios de comunicação, em diversos setores da sociedade e, especialmente, na educação, determinando inclusive as aspirações e os desejos dos homens, quer em 
nível individual, quer no âmbito grupal. Por isso, essa sociedade é parado$x a l$, pois, apesar do seu desenvolvimento, ela "é irracional como um todo. Sua produtividade é destruidora do livre desenvolvimento das necessidades e faculdades humanas" (MARCUSE, 1979, p. 14).

Sem que faça desaparecer, aparentemente, a liberdade e a autonomia individual, a sociedade tecnológica e capitalista torna o indivíduo um objeto de organização e de padronização social por meio da eficiência. O indivíduo eficiente será aquele que segue as demandas objetivas do aparato industrial, tecnológico. Desse modo, o processo da máquina dirige o pensamento e a ação do homem, e a racionalização passa a ser padronizada pelos ditames lucrativos do mercado. Por esse horizonte, a liberdade humana torna-se cada vez mais limitada, porquanto a perfeição da manipulação é tão grande que os indivíduos não percebem o seu domínio, principalmente em relação ao consumismo, tornando-se indiferentes à necessidade de mudança. Ironizando, Marcuse (1979, p. 63-64) diz o seguinte:

Se os indivíduos estão satisfeitos a ponto de se sentirem felizes com as mercadorias e os serviços que lhes são entregues pela administração, por que deveriam eles insistir em instituições diferentes para a produção de mercadorias e serviços diferentes? E se os indivíduos estão precondicionados de modo que as mercadorias que os satisfazem incluem também pensamentos, sentimentos, aspirações, por que deveriam desejar pensar, sentir e imaginar por si mesmos?

Vem, então, a seguinte indagação: como os indivíduos podem se sentir felizes, satisfeitos e livres na sociedade capitalista quando, ao mesmo tempo, lutam por felicidade, satisfação e liberdade? E como os indivíduos podem participar do seu próprio sofrimento e infelicidade?

Baseado em algumas considerações da teoria de Freud, Marcuse demonstra que grande parte dessas explicações consiste no princípio de realidade — princípio organizador da sociedade — , que se manifesta na sociedade tecnológica, capitalista, como princípio de desempenho, que, por sua vez, nega e destrona a racionalidade humana. 


\section{O princípio de desempenho como princípio de realidade na sociedade tecnológica}

Marcuse, tomando o pensamento de Freud, diz que, no desenvolvimento da civilização, "os impulsos animais convertem-se em instintos humanos sob a influência da realidade externa" (MARCUSE, 1981, p. 33). Nessa influência, cuja expressão ocorre no convívio e normas da sociedade, o homem renuncia e reprime os seus instintos primários de prazer e de satisfação. Para Freud, segundo Marcuse (1981), essa mutabilidade dos instintos humanos diz respeito à transformação do princípio de prazer em princípio de realidade. Então, o princípio de prazer, que está relacionado com a dimensão natural do homem, transmuta-se em princípio de realidade, que está relacionado com a sua dimensão social.

Com o estabelecimento do princípio de realidade, o ser humano que, sob o princípio de prazer, dificilmente pouco mais seria que um feixe de impulsos animais, converte-se num ego organizado. Esforça-se por obter "o que é útil" e o que pode ser obtido sem prejuízo para si próprio e para o seu meio vital. Sob o princípio de realidade, o ser humano desenvolve a função da razão: aprende a "examinar" a realidade, a distinguir entre bom e mau, verdadeiro e falso, útil e prejudicial. O homem adquire as faculdades de atenção, memória e discernimento. Torna-se um sujeito consciente, pensante, equipado para uma racionalidade que lhe é imposta de fora (MARCUSE, 1981, p. 35, grifo do autor).

Então o pensamento, assim como a ação do homem em sociedade, "está efetivamente subordinado ao princípio de realidade" (MARCUSE, 1981, p. 35), que se materializa em instituições e cuja finalidade se dirige para a sociabilidade do homem e para o seu desenvolvimento, tanto no âmbito da filogênese (desenvolvimento do gênero humano) como no âmbito da ontogênese (desenvolvimento do indivíduo). Com o advento da sociedade tecnológica científica, esperava-se o auge desse desenvolvimento humano, da sua razão e do seu discernimento. Entretanto, o princípio de realidade que aí se instaurou foi expresso como princípio de 
desempenho, próprio da sociedade capitalista e tecnológica, que tem a sua gênese no trabalho alienado e que se estende por toda a sociedade, incidindo sobre a mente e ação dos indivíduos.

O princípio de desempenho, que é o de uma sociedade aquisitiva e antagônica no processo de constante expansão, pressupõe um longo desenvolvimento durante o qual a dominação foi crescentemente racionalizada: o controle sobre o trabalho social reproduz agora a sociedade numa escala ampliada e sob condições progressivas. Durante uma considerável parte dessa evolução, os interesses de dominação e os interesses do todo coincidem: a utilização lucrativa do sistema produtivo satisfaz às necessidades e faculdades dos indivíduos. Para a esmagadora maioria da população a extensão e o modo de satisfação são determinados pelo seu próprio trabalho; mas é um trabalho para uma engrenagem que ela não controla, que funciona como um poder independente a que os indivíduos têm de submeter-se se querem viver [...]. Sob o domínio do princípio de desempenho, o corpo e a mente passam a ser instrumentos de trabalho alienado (MARCUSE, 1981, p. 58-59).

Podemos perceber que o princípio de desempenho como princípio de realidade internaliza no sujeito o seu domínio e suas forças. Por meio do trabalho alienado e dos complexos sociais que dele decorrem, incluindo a educação, as leis objetivas da sociedade são internalizadas, "a autoridade social é absorvida na 'consciência' e no inconsciente do indivíduo, operando como seu próprio desejo, sua moralidade e sua satisfação" (MARCUSE, 1981, p. 59). Nessa mesma obra Marcuse comenta que, sob o princípio de desempenho, o indivíduo vive a repressão e os mecanismos de controle como se fossem partes naturais da sua vida, "deseja o que se supõe que ele deve desejar" (p. 59), tornando-se razoavelmente feliz até mesmo o trabalho o faz continuar com o seu desempenho, embora a organização social, que aí tem lugar, seja imposta pelos interesses de dominação e do mercado capitalista. Aqui "o homem é avaliado de acordo com a sua capacidade de realizar, aumentar e melhorar as coisas socialmente úteis" (MARCUSE, 1981, p. 143). Quanto mais o homem produz, 
mais ele atende ao princípio de desempenho e tanto mais o sistema triunfa sobre o seu corpo e sua mente, exercendo a exploração e a repressão.

É certo que para Freud, segundo Marcuse (1981), uma civilização não repressiva é impossível, pois, para Freud, "[...] a história do homem é a história da sua repressão" (MARCUSE, 1981, p. 33) e do antagonismo eterno pela renúncia do seu prazer (princípio de prazer) em prol do princípio de realidade. No entanto, a sua própria teoria deixa brechas para uma posição diferenciada, pois, quando Freud expõe com mais detalhes as aspirações da humanidade, ele nos leva à "reivindicação de um estado em que a liberdade e a necessidade coincidam" (MARCUSE, 1981, p. 38). Sem contar também que Marcuse historiciza essa repressão da qual fala Freud - uma necessidade da convivência social, pois não se pode viver em sociedade sem leis - e a caracteriza, na sociedade capitalista e tecnológica, como mais-repressão, aquela que é desnecessária, causando dor, sofrimento e exploração e que, por sua vez, se encontra no princípio de desempenho. Desse modo, Marcuse é contra a absolutização da teoria freudiana de que o desenvolvimento da civilização só possa ocorrer com sofrimento e repressão.

Ao considerar o termo "repressão" no sentido histórico da sociedade capitalista, Marcuse o denomina de mais-repressão, que é produto desse contexto histórico específico, que tem como princípio o ter, o poder e o caráter supérfluo do consumo dos indivíduos, levando-os a crer na elevação do seu nível de vida; tudo em torno do seu caráter mercadológico e explorador. Tais ideias "pertencem ao patrimônio cultural do próprio princípio de desempenho" (MARCUSE, 1981, p. 144).

A existência da mais-repressão traz, em seu bojo, uma ideia de que qualquer ação para superá-la seria inútil. No entanto, "as sociedades exploradoras tornaram-se potências globais” (MARCUSE, 1981, p. 16), tornando-se um campo de batalha para a superação do seu próprio antagonismo. Várias são as organizações de lutas para esse fim. Uma delas pode ocorrer por meio da educação, embora ela também contenha, no contexto histórico da sociedade tecnológica e capitalista, o paradoxo 
entre o princípio de realidade e o princípio de desempenho, como é o caso da educação brasileira.

\section{O paradoxo da educação brasileira}

A educação é um processo que está presente em toda a vida da pessoa, posto que é por meio dela que o homem constrói a sua sociabilidade, como dizem Mesquida, Santos e Sampaio (2002, p. 2): “[...] desde que o homem é homem a educação se apresenta como um elemento fundamental da construção da comunidade e da subjetividade." Portanto, a educação é "um processo de vida, de construção e de experimentação", porém ela se insere sempre num contexto histórico e, nesse sentido, carrega a marca do modo de produção da sociedade da qual se insere. É assim que a educação na sociedade capitalista e tecnológica segue a sua lógica de dominação e reprodução, amparada pelo princípio de desempenho.

No seu livro Educação para além do capital, Mészáros afirma que "as determinações gerais do capital afetam profundamente cada âmbito particular" (MÉSZÁROS, 2008, p. 43, grifo do autor), com as suas influências na educação, incluindo as instituições formais. Estas estão estritamente "integradas na totalidade dos processos sociais [...] em sintonia com as determinações educacionais gerais da sociedade como um todo" (MÉSZÁROS, 2008, p. 43, grifo do autor). Trata-se aqui da educação no seu sentido mais amplo, promovendo a internalização pelos indivíduos da reprodução do sistema pelo domínio do capital. No entanto, também "as instituições formais de educação certamente são partes importantes do sistema global de internalização" (MÉSZÁROS, 2008, p. 44). Nesse sentido, a educação formal pode cumprir o seu papel para a reprodução e/ou para a transformação do princípio de desempenho do qual fala Marcuse.

Em meados de 1996, na educação brasileira, por meio da sua Lei de Diretrizes e Bases da Educação Brasileira (LDB), havia uma esperança de romper, pelo menos em parte, com esse princípio de desempenho, posto que se tentava seguir um dos princípios da Constituição Brasileira 
de 1988, ao defender, no seu artigo 205, que "A educação, direito de todos e dever do Estado e da família, será promovida e incentivada com a colaboração da sociedade, visando ao pleno desenvolvimento da pessoa, seu preparo para o exercício da cidadania e a sua qualificação para o trabalho". Por esse viés, a LDB referente à Lei n ${ }^{\circ}$ 9.394, de 20 de dezembro de 1996, no seu artigo $2^{\circ}$, reafirma essa prerrogativa da Constituição, inclusive destacando a finalidade da Educação voltada para "[...] o pleno desenvolvimento do educando, seu preparo para o exercício da cidadania e a sua qualificação para o trabalho" (BRASIL, 1996).

Passados vinte e dois anos dessa LDB, os seus princípios, em sua grande maioria, parecem cair por terra. A começar pelos seus artigos $1^{\circ}$ e $2^{\circ}$, que destacam o processo formativo e a preparação para o trabalho. Mas qual trabalho? Na realidade, o pleno desenvolvimento da pessoa e o seu preparo para o exercício da cidadania implicariam uma educação omnilateral e formativa. No entanto, ela tem sido ofuscada pelo princípio de desempenho da sociedade capitalista e tecnológica a partir do momento em que a "qualificação para o trabalho" se insere nos parâmetros do capital, ou seja, trata-se de uma educação voltada para os interesses do mercado capitalista, para a competição e para o consumo. Tudo isso tem proporcionado a perda da qualidade da formação e o aumento da privatização de escolas e de faculdades. Nesse sentido, Mészáros (2008, p. 45, grifo do autor) afirma que as soluções educacionais formais, "[...] mesmo algumas das maiores, e mesmo quando são sacramentadas pela lei, podem ser completamente invertidas, desde que a lógica do capital permaneça intacta como quadro de referências orientador da sociedade".

Esse tem sido um dos maiores paradoxos da educação brasileira: defende-se, em sua legislação, uma educação formativa, cidadã, pública e de qualidade, amparada pelos princípios expressos no seu artigo $3^{\circ}$, principalmente ${ }^{2}$, e, ao mesmo tempo, observa-se uma prática educacional

2 Sintetizando esses princípios, podemos destacar o seguinte: igualdade de condições para a permanência na escola; liberdade de aprender, ensinar e pesquisar; pluralismo de ideias e de concepções pedagógicas; respeito à liberdade e à tolerância; gratuidade no ensino público; 
carente de qualidade e de formação, quer seja no âmbito público, cuja direção é preparar mão de obra barata, quer seja no âmbito privado, no qual o aluno não passa de uma mercadoria a partir da qual "os donos" das escolas e faculdades vão obter algum lucro e perpetuar o poder. Em última instância, a educação formal brasileira termina por ser uma "fábrica de diplomas", cujo interesse é preparar os indivíduos para atender às necessidades do mercado (eficiência e utilidade) e não promover uma formação "omnilateral" da qual fala Marx ao referir-se à educação do homem enquanto apropriação do seu ser de uma "maneira omnicompreensiva" (MARX, 1989, p. 196). Na educação brasileira, isso não ocorre; ao contrário, ela é unilateralizada, unidimensional: o desenvolvimento da pessoa é diluído na qualificação única e exclusivamente para o mercado do trabalho que possa promover o princípio de desempenho. Outros paradoxos da educação brasileira, decorrentes desse mais amplo, podem ser citados aqui. A título de exemplo podemos dizer que: em parte, ela é conscientizadora, mas é também, e predominantemente, alienadora; coloca-se como formadora, mas se detém na instrução; tem um discurso potencializador da liberdade, mas remete os indivíduos à escravidão do sistema pelo consumismo, violência, etc.; fomenta esclarecimento e autonomia, mas os indivíduos ainda se encontram em sua menoridade, como diz Kant ${ }^{3}$.

Então, a educação formal brasileira, absorvendo o ideário da sociedade capitalista e tecnológica sob o princípio de desempenho, termina por contribuir, quando muito, apenas para a instrução que atenda às necessidades do mercado. Temos aí o maquiamento da formação humana que poderia contribuir para o advento de um novo princípio de realidade. No entanto, a unidimensionalidade da educação sob o prisma da sociedade tecnológica empobrece a formação, levando-a, pois, à alienação, à

valorização do profissional da educação escolar; gestão democrática do ensino público; valorização da experiência extraescolar; vinculação entre a educação escolar, o trabalho e as práticas sociais.

3 Segundo Kant (1974, p. 100, grifo do autor), a menoridade se refere à falta de esclarecimento, que consiste na "[...] saída do homem de sua menoridade, da qual ele próprio é culpado. A menoridade é a incapacidade de fazer uso do seu entendimento sem a direção de outro indivíduo". 
coisificação e à manipulação da consciência do indivíduo. Ora, a verdadeira felicidade não está no mero sentimento de satisfação, "[...] a felicidade envolve conhecimento: é a prerrogativa do animal rationale" (MARCUSE, 1981, p. 102, grifo do autor), mas, com a alienação e o declínio da consciência, o conhecimento passa a ser administrado e condicionado, pois o indivíduo não tem consciência do que realmente se passa: "a máquina esmagadora de educação e entretenimento une-o a todos os outros indivíduos, num estado de anestesia do qual todas as ideias nocivas tendem a ser excluídas" (MARCUSE, 1981, p. 102, grifo nosso). Marcuse comenta que essa anestesia geral torna os indivíduos pretensamente felizes.

É assim que se encontra a atual educação brasileira. Quanto mais aumenta o número de instituições (escolas, faculdades e universidades), e ainda assim continua em número insuficiente, mais há perdas de qualidade e de caráter realmente formativo. Assistimos hoje ao crescimento da violência (principalmente nas escolas públicas) e/ou da depressão. A juventude está perdendo o parâmetro de uma vida social coletiva, ética, solidária, na qual possam se recuperar os valores realmente humanos, justos e igualitários, deixando de lado a competição, o egoísmo, a ânsia pelo ter e possuir.

Frente à expectativa de uma concretização real do que rege a LDB de 1996, logo após a sua promulgação, Joaquim Severino já dizia (1997, p. 55) o que segue:

As pessoas que se acham historicamente concernidas pela educação e que disso têm alguma percepção subjetiva nutrem grandes expectativas em relação à nova LDB. Por maiores que tenham sido suas frustrações históricas, uma esperança sempre renasce, reafirmando quase que arquetipicamente sua fé na eficácia da legislação, reinaugurando-a como instrumento mediador da realização de efeitos sociais, capazes de transformar a realidade, tornando a sociedade brasileira cada vez mais humana, mais justa e mais equitativa.

Ainda estamos nessa busca. Porém, é preciso ter claro que a educação formal não está isolada do conjunto social. Por esse motivo, é muito grande o esforço, mas não impossível, para se obter, ainda que 
minimamente, uma formação na qual não predominem os ditames do capitalismo, e sim para uma formação intelectual, crítica e humana. É a partir desse esforço que, gradualmente, se pode romper com a dominação e gerar uma nova sensibilidade para potencializar novos valores e um novo princípio de realidade para além do princípio de desempenho. É claro que a educação formal sozinha não vai transformar o mundo, mas ela é um potencial crítico para a geração de uma nova racionalidade a partir da grande recusa do que está dominantemente posto.

\section{Para concluir: a saída do paradoxo e a grande recusa}

Vimos que, para Marcuse, o progresso civilizatório tem as suas especificidades no contexto histórico, tirando assim o caráter a-histórico da concepção freudiana. É nesse sentido que, no pensamento de Marcuse, ultrapassando a repressão freudiana, a mais-repressão será o além do socialmente necessário para a sociabilidade humana; a mais-repressão é a exigência da dominação e da manutenção do princípio de desempenho como princípio de realidade, que se baseia no trabalho alienado e na competitividade.

A grande recusa "é o protesto contra a repressão desnecessária, a luta pela forma suprema de liberdade — viver sem angústia" (MARCUSE, 1981, p. 139). Aqui se instaura a própria negação do princípio de desempenho. Não se trata de renegar o desenvolvimento tecnológico em si, mas sim o seu caráter mais-repressor, que proporcionou o advento e a manutenção do princípio de desempenho.

A negação do princípio de desempenho emerge não contra, mas com o progresso da racionalidade consciente; pressupõe a mais alta maturidade da civilização. As próprias realizações do princípio de desempenho intensificaram a discrepância entre os processos do inconsciente arcaico e da consciência do homem, por uma parte, e as suas potencialidades concretas, por outra (MARCUSE, 1981, p. 139, grifo do autor). 
A emergência de um novo princípio de realidade, um princípio não repressivo modificaria, mas não destruiria, a organização social do trabalho no sentido de que é por meio dele que o homem gera a sua sociabilidade. O que seria destruído é o trabalho alienado e, com ele, o princípio de desempenho, que consiste na "produtividade". Portanto, é preciso voltar-se "[...] contra a subjugação do homem à sua labuta. Emancipada dessa escravidão, a produtividade perde o seu poder repressivo e impulsiona o livre desenvolvimento das necessidades individuais" (MARCUSE, 1981, p. 144), liberando, assim, os domínios do trabalho alienado.

A educação, incluída a sua dimensão formal, pode ser considerada como um dos palcos de luta nessa direção. É certo que ela é considerada como um forte instrumento de reprodução das desigualdades, de alienação e de dominação, fazendo valer o princípio de desempenho; mas ela também pode ser considerada como uma das mediações de grande peso para o esclarecimento e a conscientização, que consiste, por sua vez, no primeiro e grande passo para a transformação.

Para Marcuse, as forças potenciais de transformação social estão postas. Essas forças "apresentam o potencial para a emergência de uma estrutura de caráter em que os impulsos emancipatórios ganham ascendência sobre os compensatórios" (MARCUSE, 1999a, p. 148). O nosso autor salienta ainda que o protesto contra a sociedade burguesa não surge de atitudes desrespeitosas, e sim da rejeição de antigos valores e do estabelecimento de novas atitudes. Cita, como exemplo, a reforma da universidade, que deve ser levada a cabo na própria universidade, e não tomar a forma da sua destruição, pois "[...] destruir a universidade é cortar o galho em que sentamos. Por que afinal de contas é na universidade que a oposição cresce, que a oposição é educada e se educa, e destruir a universidade pode causar um prejuízo maior para nós que para eles" (MARCUSE, 1999a, p. 70). Esse exemplo de Marcuse é um pequeno demonstrativo do potencial transformador da educação.

Ressaltamos que é preciso romper com a amálgama do princípio de desempenho por meio do esclarecimento e da conscientização, libertando a consciência alienada da competitividade burguesa. $\mathrm{O}$ 
esclarecimento, em si e por si, não transforma a realidade, mas poderá levar os indivíduos a perceber a dinâmica do princípio de realidade mais-repressivo e buscar caminhos para a sua superação e para o estabelecimento de um novo princípio de realidade que tenha como fim o bem viver da humanidade, com uma nova "estrutura pulsional dos indivíduos", de tal modo que os seus desejos e aspirações estejam voltados para valores superiores da generidade humana, e não para os valores de uma sociedade baseada em competições, instrumentalidade do ter e do poder. Tudo isso é um convite à grande recusa e a uma possibilidade histórica.

Portanto, é preciso compreender os antagonismos dessa sociedade e o paradoxo que daí decorre tanto em relação aos indivíduos, como em relação à sociedade como um todo. Em relação aos indivíduos, temos os seguintes pares: felicidade e infelicidade; satisfação das necessidades e altas carências; consumos e desperdícios; sensação de liberdade e ânsia por liberdade, etc. Em relação à sociedade, podemos destacar o fato de que ela alcançou um alto progresso com o desenvolvimento das ciências e das tecnologias, mas, ao mesmo tempo, ela vem se delineando pela carência e necessidade da maior parte da sua população, predominando ainda a pobreza e a infelicidade - sem contar com a crise dos valores humanos que a sociedade competitiva provoca.

No caso da educação brasileira, o grande paradoxo consiste centralmente no fato de que tivemos e temos a promulgação de uma LDB que, na sua origem, trazia a esperança da universalização do ensino, em todos os níveis, com qualidade e promessa de formar para a cidadania e para os valores humanos superiores; no entanto, vivemos hoje uma educação com grande perda de qualidade no âmbito público, cuja direção se volta para a formação de mão de obra barata e, no âmbito particular, temos uma educação com um caráter eminentemente mercadológico e não formativo. Aliás, tanto no âmbito público quanto no privado, em última instância, percebe-se a falta desse caráter formativo.

Para finalizar, reafirmamos a necessidade de negar essa sociedade modelada pela racionalidade tecnológica e competitiva. Essa negação não significa a luta para a obtenção de mais bens "supérfluos", e sim 
consiste na "luta coordenada contra qualquer restrição ao livre jogo das faculdades humanas, contra a labuta [...]" (MARCUSE, 1981, p. 145). Isso envolveria uma decisiva mudança na dinâmica de controle por meio do princípio de desempenho, o que levaria a um novo princípio de realidade e a uma nova experiência do ser que transformaria a atual existência humana. Nesse sentido, Marcuse afirma que "na atual situação existem praticamente todos os meios técnicos, naturais e intelectuais para criar uma sociedade justa e livre para todos os homens" (MARCUSE, 1999a, p. 126).

O grande passo para essa mudança consiste no esclarecimento e na crítica. Ela denuncia a dominação da sociedade tecnológica, capitalista e unidimensional. Este é o primeiro passo para uma ação política, para a grande recusa do paradoxo da sociedade e, por extensão, da educação brasileira. Teremos aí a supressão da mais-repressão, a possibilidade de uma nova razão e de uma nova moral social e individual.

\section{Referências}

BRASIL. Constituição da República Federativa do Brasil: promulgada em 5 de outubro de 1988. São Paulo: Atlas, 1991.

BRASIL. Lei n 9.394, de 20 de dezembro de 1996. Estabelece as diretrizes e bases da educação nacional. Diário Oficial [da] República Federativa do Brasil, Poder Executivo, Brasília, DF, 20 dez. 1996.

KANT, I. Resposta à pergunta: que é esclarecimento? (aufklärung). In: KANT, I. Textos seletos. Trad. Floriano de Sousa Fernandes. Petrópolis: Vozes, 1974. p. 100-117.

MARCUSE, H. A ideologia da sociedade industrial: o homem unidimensional. Trad. Giasone Rebuá. 5. ed. Rio de Janeiro: Zahar, 1979.

MARCUSE, H. Eros e civilização: uma interpretação filosófica do pensamento de Freud. Tradução de Álvaro Cabral. 8. ed. Rio de Janeiro: Zahar, 1981. 
MARCUSE, H. A grande recusa hoje. Trad. Isabel Loureiro e Robespierre de Oliveira. Petrópolis: Vozes, 1999a.

MARCUSE, H. Algumas implicações sociais da tecnologia moderna. In: KELLNER, D. Tecnologia, guerra e fascismo. Trad. Maria Cristina Vidal Borba. São Paulo: UNESP, 1999b. MARX, K. Manuscritos econômico-filosóficos. Trad. Artur Mourão. Lisboa: Edições 70, 1989. MESQUIDA, P.; SANTOS, M. do S. dos; SAMPAIO, A. Do conceito de educação à educação no neoliberalismo. Revista Diálogo Educacional, Curitiba, v. 3, n. 7, p. 165-178, set./dez. 2002.

MÉSZÁROS, I. A educação para além do capital. Trad. Isa Tavares. 2. ed. São Paulo: Boitempo, 2008.

SEVERINO, A. J. Os embates da cidadania: ensaio de uma abordagem filosófica da nova LDB. In: BRZEZINSKI, I. (Org.) et al. LDB interpretada: diversos olhares se entrecruzam. São Paulo: Cortez, 1997. p. 53-64.

Recebido: 30/09/2018

Received: 09/30/2018

Recibido: 30/09/2018

Aprovado: 29/10/2018 Approved: 10/29/2018 Aprobado: 29/10/2018 